\title{
Research on Promoting the Development of Electronic Information Industry Under the COVID-19 Epidemic
}

\author{
Yidan $\mathrm{Xu}^{1} \mathrm{Yu} \mathrm{Liu}^{2, *}$ Jiayi Xue ${ }^{1}$
}

\author{
${ }^{1}$ School of Public Affairs and Administration, University of Electronic Science and Technology of China, Chengdu, \\ Sichuan 611731, China \\ ${ }^{2}$ School of Management and Economics, University of Electronic Science and Technology of China, Chengdu, Sichuan \\ 611731, China \\ *Corresponding author. Email: liuyu0414@uestc.edu.cn
}

\begin{abstract}
Against the background of the prevention and control of the COVID-19 epidemic, this paper explores the role of electronic information technology, analyzes the problems existing in China's electronic information industry, and provides suggestions for the future development of the electronic information industry from the aspects of cultivating talents, building industrial parks, improving infrastructure, and broadening industrial application scenarios, so as to improve the policy system for the introduction of talents, facilitate the construction of data centers, promote the introduction of electronic information industry projects, and comprehensively improve the level of informatization and other development proposals.
\end{abstract}

Keywords: COVID-19 epidemic, electronic information industry, countermeasures and suggestions

\section{INTRODUCTION}

The prevention and control of COVID-19 epidemic is under great pressure, and characterized by heavy workload, difficulty in screening and control, multiple management, repetitive work, and difficulty in mastering progress. Each county (city) needs to strengthen the investigation and publicity of the epidemic prevention and control work. Electronic information technology plays an important role in this process. In this context, the future development path of electronic information industry is worthy of further consideration.

\section{CARRYING OUT EPIDEMIC PREVENTION}

\section{AND CONTROL WITH THE HELP OF} INFORMATION TECHNOLOGY

Cloud computing, big data, artificial intelligence, mobile collaborative office and other technologies have been repeatedly used by all walks of life in the campaign against the epidemic and played an important role. During the epidemic period, Scientists of Alibaba Dharma Institute led by Dr. Gu Fei, a Harvard graduate, quickly set up a whole-genome detection and analysis platform within a short period of time, which was immediately launched in Zhejiang center for disease control and prevention. Baidu big data and analysis technology provides decision support for epidemic control and work and production resumption. Baidu AI temperature measurement system and intelligent outbound call platform have contributed to epidemic screening, greatly improving the efficiency of epidemic prevention and control. In addition, DingTalk and other mobile collaborative office platforms bear the traffic peak of online office and online education.

In the COVID-19 prevention and control work, various electronic information industrial enterprises play their own technical advantages and product expertise, make full use of Internet of things, 5G communication, portrait recognition, big data analysis, artificial intelligence, digital media, network security and other technologies, construct big data platform for epidemic prevention and control, build community grid epidemic prevention guards, build epidemic analysis and reporting system, and provide epidemic housekeeper-AI voice report and external call service, etc. They have contributed scientific and technological strength to fight the epidemic, and actively participated in the epidemic prevention and control.

At the same time, the medical and health conditions in some remote rural areas are bad, the epidemic prevention and control is incomplete, the health detection ability is weak, the ability of medical staff to prevent and control the epidemic situation is uneven, and the protection publicity is not in place. Therefore, it is necessary to give full play to the technical advantages of the electronic information industry to implement accurate measures and use professional technology and products to guarantee the system stability, unobstructed information, scientific decision-making and scheduling, 
so as to provide solid scientific and technological strength for fighting against the epidemic and prevent the import, spread and output of the epidemic. At present, some telecommunication companies have actively cooperated with the Health Commission to build a dynamic monitoring convergence platform for the prevention and control of health detection card points covering the whole region, set up a monitoring convergence platform for the regional headquarters free of charge, and open video surveillance for the most cutting-edge health detection card points for epidemic prevention and control free of charge, so as to realize regional management respectively. The video monitoring system built in the front line of epidemic prevention and control will give full play to the advantages of real-time viewing, multi terminal access, cloud video storage and return transmission, promote the sharing of information and data, meet the interaction and cooperation between the command and the card points, help the emergency command departments to provide strong data support for the epidemic prevention and control and leadership decision-making, and increase the power of the checkpoint to prevent and control the epidemic situation by means of information technology.

With the sudden increase in remote meetings and communications during the epidemic, and in order to help units fight the COVID-19 epidemic, digital media provides "cloud video" conferencing service and "interphone" multimedia intercom services in response to this situation, realizing conference communication, one-to-one or group calls and video functions anytime and anywhere and improving the efficiency and immediacy of communication in epidemic prevention and treatment. All localities should strengthen the organic combination of long-term economic growth goals in response to the epidemic situation [1], and take epidemic prevention and control as the breakthrough point to promote the development of regional electronic information industry.

\section{RESTRICTIVE FACTORS OF CHINA'S ELECTRONIC INFORMATION INDUSTRY}

\section{A. Lacking electronic information talents}

At present, China has formed a relatively systematic and perfect electronic information industry system, but there are still a large number of poor people with relatively low cultural quality, education level and poor employment skills in some regions. Therefore, it is difficult to provide labor force for the electronic information industry. Moreover, there are some problems, such as the talent introduction, stability and retention, and the serious lack of professional and technical personnel and management personnel.

\section{B. Incomplete industrial chain and great pressure of industrial transformation and upgrading}

At present, China's modern service industry still needs further development, which can provide limited support for the large-scale development of electronic information industry. In some regions, the primary and secondary industries account for a large proportion, and the homogenization problems in the industrial development and product positioning are prominent, and there is a lack of necessary division of labor and cooperation, which will hinder the construction of electronic information industry and the extension of industrial chain in the future. At present, the development of most "enclave" parks in China is still in the exploratory stage, and there are some problems such as scattered layout, small scale, weak comprehensive bearing capacity and low level of industrial agglomeration.

\section{Incomplete infrastructure}

On the one hand, the communication infrastructure is relatively backward. Although some achievements have been made in the construction of communication and other infrastructure in China, there are still some problems such as no communication coverage and no fiber broadband network in some administrative villages, which seriously hinder the development of $5 \mathrm{G}$ technology. On the other hand, the supporting infrastructure such as parks, transportation and water conservancy facilities for the development of electronic information industry is not complete, which has greatly hindered the production and talent introduction.

\section{SUGGESTIONS FOR THE DEVELOPMENT OF CHINA'S ELECTRONIC INFORMATION INDUSTRY}

\section{A. Strengthening the industrial foundation with the help of resource advantages}

The electronic information industry has the characteristics of wide industrial coverage and rapid technology update. At present, many cities in China are actively building industrial incubation centers and science and technology pilot areas based on resource characteristics and location advantages. At the same time, with the continuous popularization of intelligent products, the demands of consumers continue to grow, which forces the development of electronic information industry in the region and promotes the transformation and upgrading of traditional industries.

For this epidemic, most regions rely on local electronic information science and education, industries and resources to increase scientific and technological research on the COVID-19 prevention and control, complement the shortcomings of epidemic management and control technology, and accelerate the research and 
development of new technologies, methods, products and equipment for epidemic prevention and control.

\section{B. Strengthening the development and cultivating electronic information talents}

Talent is the key and power source to promote the development of electronic information industry. First of all, it is required to improve the policy system for the introduction and use of talents. It should not only provide policy support for the introduction methods, but also strengthen policy support for the development and training of talents and expand the scope of talent introduction. Secondly, it is better to strengthen the incentive support for personnel training, pay attention to the development and training of existing talents, and also pay attention to mobilizing talents' enthusiasm and innovation motivation while introducing talents. In addition, it is necessary to vigorously carry out the work of "flexible introduction of talents", improve the supporting policies, and introduce talents urgently needed in characteristic industries and public services. In particular, it is necessary to strengthen the cooperation with universities in politics, industry, learning and research. With the help of the "enclave" park, it is better to encourage the flexible and free flow of "enclave" talents through diversified ways such as project technology development and scientific and technological service consultation. It is better to rationalize the structure of talent team, and cultivate high-quality electronic information innovation talent team.

\section{Focusing on industrial parks and facilitating the construction of data centers}

Big data technology can play an all-round supporting role in technology, management and other aspects of the intelligent information industry [2], and can greatly promote the improvement of the electronic information industry. Faced with the problems of weak foundation and lack of talents, the electronic information industry needs to strengthen the core competitiveness of the industrial chain and realize the leapfrog development of the industry through "chain supplement", "chain strengthening" and "chain building". The construction of industrial park is one of the important measures to "supplement the chain" and "strengthen the chain". The construction of industrial park is conducive to the construction of a coordinated and unified platform to promote the unified standards and management of enterprises in the park. It is necessary to accelerate the construction of electronic information industrial park, provide information technology with a unified platform, relax business license and optimize the approval process, reduce taxes and fees in all links of the industrial chain, ensure the collection of raw materials, and stabilize transportation and processing throughout the year, so as to make the whole industrial chain more secure and efficient, promote the infiltration and exchange between industries, and promote the replacement of resources in the park and carry out cooperation.

In order to develop the electronic information industry, it is necessary to optimize the planning, upgrade the park, give full play to the resource endowment advantages such as water and electricity enrichment, and adhere to the application orientation. In the construction and development of the park, it is necessary to introduce large and strong enterprises, take the market as the guide and industrial projects as the starting point, and strive to solve the bottleneck problems of funds and talents in the construction of information infrastructure. It is necessary to coordinate and strengthen the cooperation between government, industry, university and research institutions, give full play to the advantages of electronic information technology in colleges and universities, and increase technical support for the industrial chain with the help of scientific research and industrial strength of colleges and universities.

\section{Promoting the introduction of electronic information industry based on project}

In the process of epidemic prevention and control, UAV, online education and other emerging formats have played an important role, which also shows the positive effect that new technology can bring to the improvement of management level and social governance ability. Research by Xu Nini et al. (2020) shows that the government's subsidy policy is effective for the comprehensive and systematic innovation of the electronic information industry, and it is also crucial to its development [4]. Therefore, local governments should seize the opportunity to issue special policies, introduce electronic information enterprises and industrial chain cooperative enterprises that benefit the people's livelihood, promote the combination of industry, university and research by means of institutional support, organizational support and special plans, and provide element guarantee for major electronic information industrial projects according to procedures. It is necessary to support large-scale enterprises to extend downward, take active and effective methods to expand project development, and provide certain guidance and consulting services for technical difficulties encountered in project selection, approval and construction activities. And then, it is required to coordinate to solve the practical problems, such as electronic information enterprise project approval, land use and environmental impact assessment. In addition, it can establish a platform for scientific and technological innovation, promote the organic combination of various engineering centers, R\&D centers, key laboratories of the state, universities and electronic information technology enterprises, and 
promote the transformation of achievements. Taking UAV enterprises as an example, there are many mountains and rivers in China, and the masses live together in a small range of mountainous areas, so it is relatively difficult to collect and publicize information. UAV helps to prevent and control the epidemic situation. Through cloud command and dispatch, the UAV greatly improves the operation efficiency in the front line, without omission and dead angle. UAV provides new possibilities for the development of social services in the future. During the epidemic, local governments can establish cooperative relations with UAV production enterprises and establish UAV dispatching and command centers of district and county governments by attracting businesses and investment, which will certainly provide favorable conditions for the development of local public utilities and new growth points for UAV production and other industries.

\section{E. Improving infrastructure and seizing the opportunity of information development}

To comprehensively improve the level of informatization is an important guarantee for the development of electronic information technology industry, so it is necessary to pay attention to the construction of information infrastructure. First of all, it is required to promote the construction of new generation mobile communication, Internet and other network facilities and comprehensive transmission bear-networks, and further strengthen the integration of "three networks". In the process of ensuring the development of the electronic information industry, it should coordinate the three kinds of network coverage, including wired, wireless and satellite. The masses can share modern civilization, and the further development of the industry can be driven with the needs of the masses. At the same time, it is necessary to improve the level of rural informatization, promote the progress of communication, computer, Internet and information technology, and then improve the overall efficiency of logistics enterprises and the connection between transportation, distribution, storage and other logistics links, so as to help the development of rural ecommerce [5].

In addition, it is required to actively prepare for the construction of $5 \mathrm{G}$ base station, seize the opportunity of 5G construction, and promote the coordinated development of $5 \mathrm{G}$ construction and networking project. It is better to actively connect with China Tower Company, make use of the existing site resources of China Tower Company, and promote the rapid distribution of $5 \mathrm{G}$ low-cost network. In order to save investment, land and other resources, it can actively explore $5 \mathrm{G}$ and $4 \mathrm{G}$ co-construction and sharing. At the same time, it is necessary to strengthen the use of public resources such as stations, tourist attractions, parks, etc., make full use of building floors, walls, monitoring poles, power towers, etc. to meet the demand for $5 \mathrm{G}$ mount, increase social resources reserve in key areas covered by $5 \mathrm{G}$, and do a good job in assessing the carrying capacity of social pole and tower.

\section{F. Promoting people's livelihood projects with the help of information technology}

To promote the development of electronic information technology and products and improve the effective promotion of electronic information industry, its fundamental purpose is to serve the people. With the continuous emergence of technology to help prevent and control epidemic situation, electronic information technology will become an important prospect for the development of people's livelihood in the future. At present, in order to ensure the promotion of "efficient prevention and control, scientific management and control, unified regulation and control", the establishment of intelligent epidemic prevention and control platform has become an important construction direction for governments at all levels to effectively carry out epidemic prevention and control work. Relying on science and technology, it is necessary to give full play to the advantages of network technology, help the platform become the "fresh force" of epidemic prevention and control, and constantly explore innovative technology to help the epidemic prevention and control. Using modern information technology such as $5 \mathrm{G}$, artificial intelligence, video communication, telemedicine and other modern information technology means, the establishment of epidemic prevention and control monitoring, telemedicine collaboration, isolation personnel monitoring, public security management, publicity and reporting, mobile office and video service platform can better promote the prevention and control of epidemic situation with science and technology. Fighting the COVID-19 epidemic is also a test of the degree of growth and social effectiveness of the growing online government service [6]. The epidemic has revealed that there are still many problems in China's online government service, and it is necessary to deepen the construction and application of integrated online government service platform with the help of the development of electronic information industry.

In the post-epidemic stage, local governments can further promote the construction of big data platform for epidemic prevention and control, which is built by the communication companies and the Health Commission during the epidemic period, covering the health inspection card points, organically combine the development of big data industry with the improvement of quality and efficiency of grass-roots governance, the improvement of social security, and the development of global tourism, strengthen the construction of public information platform, and promote the wide application of Internet in government management and other fields. 
The significance of promoting the sharing of various information resources, such as e-government and ecommerce, municipal management, is not only to promote the rapid development of corresponding electronic information industry, but also to popularize the new economic dividend to different fields of economic society and more people [7]. It is better to build a cross-regional business processing and consulting platform for convenient service, accelerate the regional integration of medical insurance and social security, strengthen the construction of information security and data integration, improve the emergency communication system, and vigorously promote the construction of intelligent big data.

\section{CONCLUSION}

Under the COVID-19 epidemic, China's electronic information industries have taken measures to coordinate the resumption of production and production, and continuously improved the supply and support capabilities. They have made positive contributions to the good effect of epidemic prevention and control in China. In the post-epidemic era, the development of electronic information industry should be extensively explored on the basis of COVID-19 epidemic prevention and control, so as to further promote industrial transformation and upgrading.

\section{References}

[1] Zhu Jun, Zhang Shucui, Li Jianqiang. Economic Effect and Fiscal Policy Assessment of COVID-19 Outbreak [J]. Review of Economy and Management, 2020, 36(3): 21-32. (in Chinese)

[2] $\mathrm{Xu}$ Jianxiong. Research on the Intelligent Electronic Information Industry in the Big Data Era [J]. Economic Research Guide, 2018, (1): 33-34. (in Chinese)

[3] Du Wenhong, Huang Zhongdong. Research on the transformation and upgrading of Guangxi's electronic information industry [J]. Guangxi Social Sciences, 2015, (10): 37-40. (in Chinese)

[4] $\mathrm{Xu} \mathrm{Ni} \mathrm{Ni,} \mathrm{Guo} \mathrm{Junhua.} \mathrm{The} \mathrm{Research} \mathrm{on} \mathrm{the} \mathrm{Impacts} \mathrm{of}$ Government Subsidies on the Technological Innovation of Electronic Information Industry--Empirical Evidence from Chinese Listed Companies [J]. Journal of Industrial Technological Economics, 2020, 39(6): 13-20. (in Chinese)

[5] Zhang Xiaobo. Analysis on the Construction of Rural Logistics Network System in the Internet Era [J]. Journal of Commercial Economics, 2020, (9): 119-121. (in Chinese)

[6] Wang Rui. Practice and thinking on online government service in the "post-epidemic" era [J]. China Economic and Trade Guide, 2020, (17): 148-149. (in Chinese)

[7] Yang Hutao. The new meaning of new infrastructure [J]. Red Flag Manuscript, 2020, (10): 24-26. (in Chinese) 